\title{
EDITORIAL
}

\section{Targeting small airways in asthma: the new challenge of inhaled corticosteroid treatment}

\author{
S. Lahzami*,\# and G.G. King ${ }^{*, \#, q,+}$
}

$\mathbf{T}$ he small airways have long been considered to be important in asthma. The presence of inflammation in small airways has been well established in studies of post mortem tissue [1]. Inflammation even extends to peribronchial tissues seen in transbronchial biopsy studies [2]. In this issue of the European Respiratory Journal, the study by COHEN et al. [3] underscores the increasing interest in targeting treatment to the small airways with currently available fine-particle aerosols with median diameters of $\sim 1 \mu \mathrm{m}$. The study also highlights the as yet unproven potential of aerosol treatment in targeting the small airways and the complexities of such research. COHEN et al. [3] found that 5 weeks of ciclesonide treatment, a small-particle inhaled corticosteroid, improved alveolar exhaled nitric oxide, airway hyperresponsiveness and spirometry but not closing volume. They also found that the expiratory lung volume measured using high-resolution computed tomography (HRCT), after methacholine challenge, was smaller in the ciclesonide-treated group compared with the placebo group. However, the question as to whether ciclesonide is better than larger-particle aerosols for treating small airways in asthma remains unanswered.

Establishing the clinical significance of small airways disease is a priority if advances in asthma management are to occur; however, this has been difficult because of the challenges in measurement. Assessment of small airways continues to be a complex undertaking and includes techniques such as transbronchial biopsy, gas washout tests [4, 5], frequency dependence of compliance, intrabronchial pressure measurements [6], forced oscillation technique (FOT) measurements of resistance and reactance [7], and, more recently, imaging [3, 7-9]. The aforementioned physiological tests of small airways function are based on two characteristics of peripheral airway behaviour: nonuniformity of ventilation and airway closure [10]. Advances in imaging to probe the small airways have led to quantitative image analyses of three-dimensional image data that are based on these physiological phenomena, while providing additional information of location, pattern (localised or diffuse) and regional extent of the phenomena. Along with

*Dept of Respiratory Medicine, Royal North Shore Hospital, St Leonards, " The Woolcock Institute of Medical Research, "The Cooperative Research Centre for Asthma, Camperdown, and ${ }^{+}$The Northern Clinical School, Faculty of Medicine, University of Sydney, Sydney, Australia.

STATEMENT OF INTEREST: None declared.

CORRESPONDENCE: G.G. King, The Woolcock Institute of Medical Research, Dept of Respiratory Medicine, Royal North Shore Hospital, St Leonards, NSW 2065, Australia. Fax: 61299265520 E-mail: ggk@woolcock.org.au advances in imaging of small airways, advances in physiological measurement include using FOT to measure the distensibility of the airways [11] and multiple-breath nitrogen washout, which provides indices of ventilation heterogeneity in the intra-acinar airway zone (where gas transport occurs predominantly by diffusion) and peripheral conducting zone (predominantly convective gas transport) [5].

Despite the challenges, there is already a considerable body of evidence to support the clinical importance of small airways disease in asthma. More severe asthma is associated with greater peripheral inflammation in transbronchial biopsy tissue [2] and increased airway closure (which is likely to occur in the peripheral airways) in washout studies [4], and, as inferred by greater respiratory elastance, in FOT studies [12]. Furthermore, more uneven distribution of ventilation in the peripheral conducting airway compartment, often referred to as heterogeneity, is strongly correlated with airway hyperresponsiveness both before and after effective inhaled steroid treatment [5]. Given the important associations between airway hyperresponsiveness and airway remodelling [13], long-term decline in lung function [14], asthma severity [15] and treatment requirements [13], this further emphasises the likely clinical importance of studying small airways disease and strongly supports potential benefits of anti-inflammatory and anti-remodelling treatment of the peripheral airway compartment.

Small-particle aerosols, such as hydrofluoroalkane-134a (HFA) beclomethasone and ciclesonide, which have particle sizes around $1 \mu \mathrm{m}$ have recently become available. These formulations have been shown to have a greater lung deposition as a proportion of ex-actuator amount and a greater proportion that deposits peripherally [16]; it is therefore obvious that these small-particle aerosols should be more effective for specifically treating the peripheral airway compartment in asthma. There is little doubt from the large body of published evidence that small-particle aerosols are effective in improving clinical indices of asthma control, physiology and inflammation.

Whether small particles are better than larger particles in terms of their effect on small airway function, however, is an area of conflicting evidence. Hence, there is little to guide clinical use of fine-particle inhaled corticosteroid aerosols to make use of their superior peripheral deposition. Results of HRCT comparison between fine-particle HFA beclomethasone and largerparticle aqueous aerosol treatment showed less regional gas trapping with the fine-particle aerosol [17], whereas no difference was seen in another HRCT comparison between 
HFA beclomethasone and dry-powder inhaled steroid [18]. Neither were there any differences in the improvements in lung function between treatment groups. In contrast, a comparison of HFA beclomethasone and equi-microgram doses of fluticasone showed superiority of the former in improvements in airway closure measured by single-breath nitrogen washout [19]. In another study of peripheral airway function measured by multiple-breath nitrogen washout, changing to HFA beclomethasone following 6 weeks of treatment with a dry-powder inhaler was associated with improvements in acinar airway function in those in whom it was initially abnormal [20].

The use of HRCT to study small airways is highly technical and remains problematic. As small airways are at the lower limit of HRCT resolution, measurements of airway dimensions are themselves unreliable [21]. Hence, HRCT measurement of small airway function must be based on parenchymal measurements. However, there are many different methods of image analysis, some being fully quantitative and others semi-quantitative, with varying degrees of validation. Study designs also differ with respect to drug doses and duration, HRCT scanning technique, and measurement and control lung volume (spirometric gating), which adds to the difficulties in comparing studies. Since lung density and airway closure are highly volume dependent, control of lung volume at the time of scanning, particularly when comparing before and after interventions, must be carefully addressed in HRCT studies. Another problem facing all HRCT studies is small subject numbers, perhaps due to the complexity and radiation exposure that make some subjects reluctant to participate. This is a significant factor to consider, given that any treatment differences between small- and large-particle aerosols in terms of small airway function are unlikely to be large. All of these issues are relevant to the study by COHEN et al. [3], as well as the aforementioned HRCT studies of small airways [17, 18], and make interpretation of findings difficult. Nevertheless, there remains the possibility that there is a potential differential benefit of small-particle aerosol treatment to the small airways in asthma.

Perhaps the way forward is to make use of the underlying physiology of small airways disease on which measurements are based: nonuniformity (heterogeneity) of ventilation and airway closure described in 1969 by Brown et al. [10]. Interpretation of these complex findings could be improved by tying together, by mathematical modelling, the physiological measurements, such as those from the forced oscillation technique and washout tests, with those from image data. This is a logical approach as there are already well-developed structural and functional models of the lung to achieve this, and it is an approach that has been successfully applied to both the high-resolution computed tomography [9] and the positron emission tomography data of asthmatics [7]. Measurements of small airways using multiple methods are often made in studies of small airways; the importance of this for detecting any treatment effect is again demonstrated in the study by COHEN et al. [3]. Greater insight into treatment effects on small airways will hopefully flow from such a combined approach, as well as improvement in imaging technology, standardisation and rigour of imaging and image-analysis methods.

\section{REFERENCES}

1 Carroll N, Elliot J, Morton A, James A. The structure of large and small airways in nonfatal and fatal asthma. Am Rev Respir Dis 1993; 147: 405-410.

2 Balzar S, Wenzel SE, Chu HW. Transbronchial biopsy as a tool to evaluate small airways in asthma. Eur Respir J 2002; 20: 254-259.

3 Cohen J, Douma WR, ten Hacken NHT, Vonk JM, Oudkerk M, Postma DS. Ciclesonide improves measures of small airway involvement in asthma. Eur Respir J 2008; 31: 1213-1220.

4 in 't Veen JC, Beekman AJ, Bel EH, Sterk PJ. Recurrent exacerbations in severe asthma are associated with enhanced airway closure during stable episodes. Am J Respir Crit Care Med 2000; 161: 1902-1906.

5 Downie S, Salome C, Verbanck S, Thompson B, Berend N, King G. Ventilation heterogeneity is a major determinant of airway hyperresponsiveness in asthma, independent of airway inflammation. Thorax 2007; 62: 684-689.

6 Kaminsky DA, Irvin CG, Lundblad L, et al. Oscillation mechanics of the human lung periphery in asthma. J Appl Physiol 2004; 97: 1849-1858.

7 Tgavalekos NT, Musch G, Harris RS, et al. Relationship between airway narrowing, patchy ventilation and lung mechanics in asthmatics. Eur Respir J 2007; 29: 1174-1181.

8 Zeidler MR, Kleerup EC, Goldin JG, et al. Montelukast improves regional air-trapping due to small airways obstruction in asthma. Eur Respir J 2006; 27: 307-315.

9 Kaminsky DA, Irvin CG, Lundblad LKA, et al. Heterogeneity of bronchoconstriction does not distinguish mild asthmatic subjects from healthy controls when supine. J Appl Physiol 2008; 104: 10-19.

10 Brown R, Woolcock AJ, Vincent NJ, Macklem PT. Physiological effects of experimental airway obstruction with beads. J Appl Physiol 1969; 27: 328-335.

11 Brown NJ, Salome CM, Berend N, Thorpe CW, King GG. Airway distensibility in asthmatic and healthy adults measured by forced oscillation technique. Am J Respir Crit Care Med 2007; 176: 129-137.

12 Lutchen KR, Jensen A, Atileh H, et al. Airway constriction pattern is a central component of asthma severity. The role of deep inspirations. Am J Respir Crit Care Med 2001; 164: 207-215.

13 Sont JK, Willems LNA, Bel EH, van Krieken JHJM, Vandenbroucke JP, Sterk PJ. Clinical control and histopathological outcome of asthma when using airway hyperresponsiveness as an additional guide to long-term treatment. Am J Respir Crit Care Med 1999; 159: 1043-1051.

14 ten Brinke A, Zwinderman AH, Sterk PJ, Rabe KF, Bel EH. Factors associated with persistent airflow limitation in severe asthma. Am J Respir Crit Care Med 2001; 164: 744-748.

15 Rasmussen F, Taylor DR, Flannery EM, et al. Risk factors for hospital admission for asthma from childhood to young adulthood: a longitudinal population study. J Allergy Clin Immunol 2002; 110: 220-227.

16 Newman S, Salmon A, Nave R, Drollmann A. High lung deposition of $99 \mathrm{mTc}$-labeled ciclesonide administered via HFA-MDI to patients with asthma. Respir Med 2006; 100: 375-384. 
17 Goldin JG, Tashkin DP, Kleerup EC, et al. Comparative effects of hydrofluoroalkane and chlorofluorocarbon beclomethasone dipropionate inhalation on small airways: assessment with functional helical thin-section computed tomography. J Allergy Clin Immunol 1999; 104: S258-S267.

18 Tunon-de-Lara JM, Laurent F, Giraud V, et al. Air trapping in mild and moderate asthma: effect of inhaled corticosteroids. J Allergy Clin Immunol 2007; 119: 583-590.
19 Thongngarm T, Silkoff P, Kossack W, Nelson H. Hydrofluoroalkane-134A beclomethasone or chlorofluorocarbon fluticasone: effect on small airways in poorly controlled asthma. J Asthma 2005; 42: 257-263.

20 Verbanck S, Schuermans D, Paiva M, Vincken W. The functional benefit of anti-inflammatory aerosols in the lung periphery. J Allergy Clin Immunol 2006; 118: 340-346.

21 King GG, Carroll JD, Müller NL, et al. Heterogeneity of narrowing in normal and asthmatic airways measured by HRCT. Eur Respir J 2004; 24: 211-218. 